\title{
A study on relationship between knowledge management and organizational change in learning organizations: A case study of cable industry
}

\author{
Mohammad Emamia $^{a}$, Hamta Feridouni ${ }^{a}$, Seyed Hassan Kia ${ }^{b}$ and Maliheh Sadat Monnavaria
}

${ }^{a}$ Department of Management, Semnan Branch, Islamic Azad University, Semnan, Iran

${ }^{b}$ Member of young club, Semnan Branch, Islamic Azad University, Semnan, Iran

\section{CHRON I C L E}

\section{Article history:}

Received May 22, 2013

Received in revised format

28 August 2013

Accepted 14 September 2013

Available online

September 152013

Keywords:

Organizational change

Knowledge management

Learning organizations

\begin{abstract}
A B S T R A C T
This paper presents an empirical investigation to study the relationship between knowledge management and organizational change in one of Iranian producers of wire and cable. The proposed study of this paper designs a questionnaire consists of 23 questions in Likert scale and distributes it among 76 randomly people who work for this organization. The results of Spearman correlation coefficients show that harvest index, refining, organizing, disseminating and applying knowledge have positive and meaningful relationship with organizational change. Managers need to develop organizational change to integrate the wealth of knowledge in various sectors and having knowledge of internal and external forces.
\end{abstract}

(C) 2013 Growing Science Ltd. All rights reserved.

\section{Introduction}

During the past few years, there have been tremendous studies on the effect of organizational change on performance of organizations (Chiang, 2010). Organizations always need to prepare themselves for any significant change. Lehman et al. (2002) presented a comprehensive assessment of organizational functioning and readiness for change (ORC) based on a conceptual framework. The study concentrated on motivation and personality attributed of program leaders and staff, institutional resources, and organizational climate as an essential first step in recognizing organizational factors associated with implementing new methods into a program. The study described the rationale and structure of the ORC and demonstrated that it had acceptable psychometric properties. The results indicated the ORC could contribute to the study of organizational change and technology transfer by detecting functional barriers involved. Klarner et al. (2011) investigated the role of employee emotions during organizational change processes. They addressed some shortcomings and offered a research agenda on emotions during change, which incorporated the so far neglected view of emotions as processes that unfold during and across organizational changes.

*Corresponding author. Tel: +989124313056

E-mail address: mohammad.emami68@gmail.com (M. Emami) 
Peachey and Bruening (2012) performed an investigation on the effect of organizational change on sport firms and demonstrated that ambivalence was a salient response to change, and that intrapersonal conflict, perceived lack of institutional support, managerial turnover, and previous negative experience with change served as antecedents. Thomas and Hardy (2011) studied the literature on resistance to organizational change and identified two dominant yet contrasting approaches including the demonizing versus the celebrating of resistance to change. They explained that both of these approaches could fail to address power relations sufficiency and, in so doing, raise practical, ethical and theoretical problems in recognizing and managing change. They also proposed an alternative, more critical approach, which indicated how both power and resistance constituted organizational change and shed light on how power-resistance relations lie at the heart of organizational change. Battilana et al. (2010) inestigated the relationship between managers' leadership competencies and the likelihood that they would emphasize the various activities involved in planned organizational change implementation. They examined this relationship using data from 89 clinical managers at the United Kingdom National Health Service who used change projects over the period 2003-2004. Their results lend overall support to the proposed theory and recommended that treating planned organizational change as a generic phenomenon might mask important idiosyncrasies associated both with the various activities involved in the change implementation process and with the unique functions that leadership competencies might play in the execution of these activities.

\section{The proposed study}

In this paper, we present an empirical investigation to study the relationship between knowledge management and organizational change. The proposed study of this paper designs a questionnaire in Likert scale and distributes it among 76 randomly people work for a producer of wire and cable. There are five sub-hypotheses associated with the proposed study of this paper as follows,

1. There is a positive and meaningful relationship between harvest index and organizational change.

2. There is a positive and meaningful relationship between refining knowledge and organizational change.

3. There is a positive and meaningful relationship between organizing knowledge and organizational change.

4. There is a positive and meaningful relationship between disseminating knowledge and organizational change.

5. There is a positive and meaningful relationship between applying knowledge and organizational change.

Fig. 1 demonstrates the structure of the proposed study of this paper.

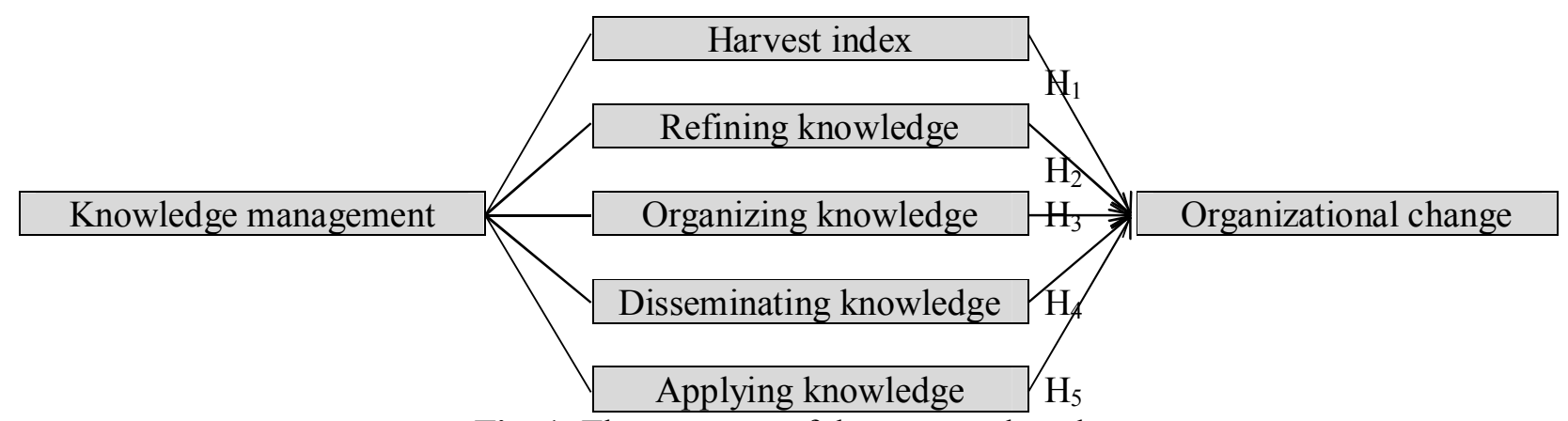

Fig. 1. The structure of the proposed study

There are two questionnaires associated with knowledge management and organizational change and Cronbach alphas have been calculated as 0.95 and 0.93, respectively. Next, we perform KolmogorovSmirnov test to verify the normality of data and Table 1 demonstrates the results of our survey. 
Table 1

The results of Kolmogorov-Smirnov test

\begin{tabular}{lccc}
\hline Variable & Kolmogorov-Smirnov value & Sig. & Result \\
\hline Harvest index & 1.244 & 0.072 & Not Normal \\
Refining knowledge & 1.259 & 0.026 & Not Normal \\
Organizing knowledge & 1.280 & 0.050 & Normal \\
Disseminating knowledge & 1.335 & 0.092 & Not Normal \\
Applying knowledge & 1.573 & 0.031 & Not Normal \\
Knowledge management & 1.344 & 0.054 & Normal \\
Organizational change & 1.175 & 0.281 & Normal \\
\hline
\end{tabular}

As we can observe from the results of Table 1, all data are not normally distributed and we, therefore, use Spearman test to verify the tests.

\section{The results}

In this section, we present details of our survey on testing various hypotheses of this survey using Spearman test. Table 2 summarizes the results of our investigation.

\section{Table 2}

The summary of testing various hypotheses using Pearson correlation (r)

\begin{tabular}{lcccc}
\hline Variable & $\mathrm{r}$ & Sig. & Error & Result \\
\hline Harvest index & 0.817 & 0.000 & 0.01 & $\sqrt{ }$ \\
Refining knowledge & 0.756 & 0.000 & 0.01 & $\sqrt{ }$ \\
Organizing knowledge & 0.677 & 0.000 & 0.01 & $\sqrt{ }$ \\
Disseminating knowledge & 0.778 & 0.000 & 0.01 & $\sqrt{ }$ \\
Applying knowledge & 0.875 & 0.000 & 0.01 & $\sqrt{ }$ \\
Knowledge management and Organizational change & 0.766 & 0.000 & 0.01 & $\sqrt{ }$ \\
\hline
\end{tabular}

As we can observe from the results of Table 2, the main hypothesis of this survey along with five other sub-hypotheses of this study have been confirmed. We have also applied Freedman test to verify the relative importance of all hypotheses of the results are summarized in Fig. 2 as follows,

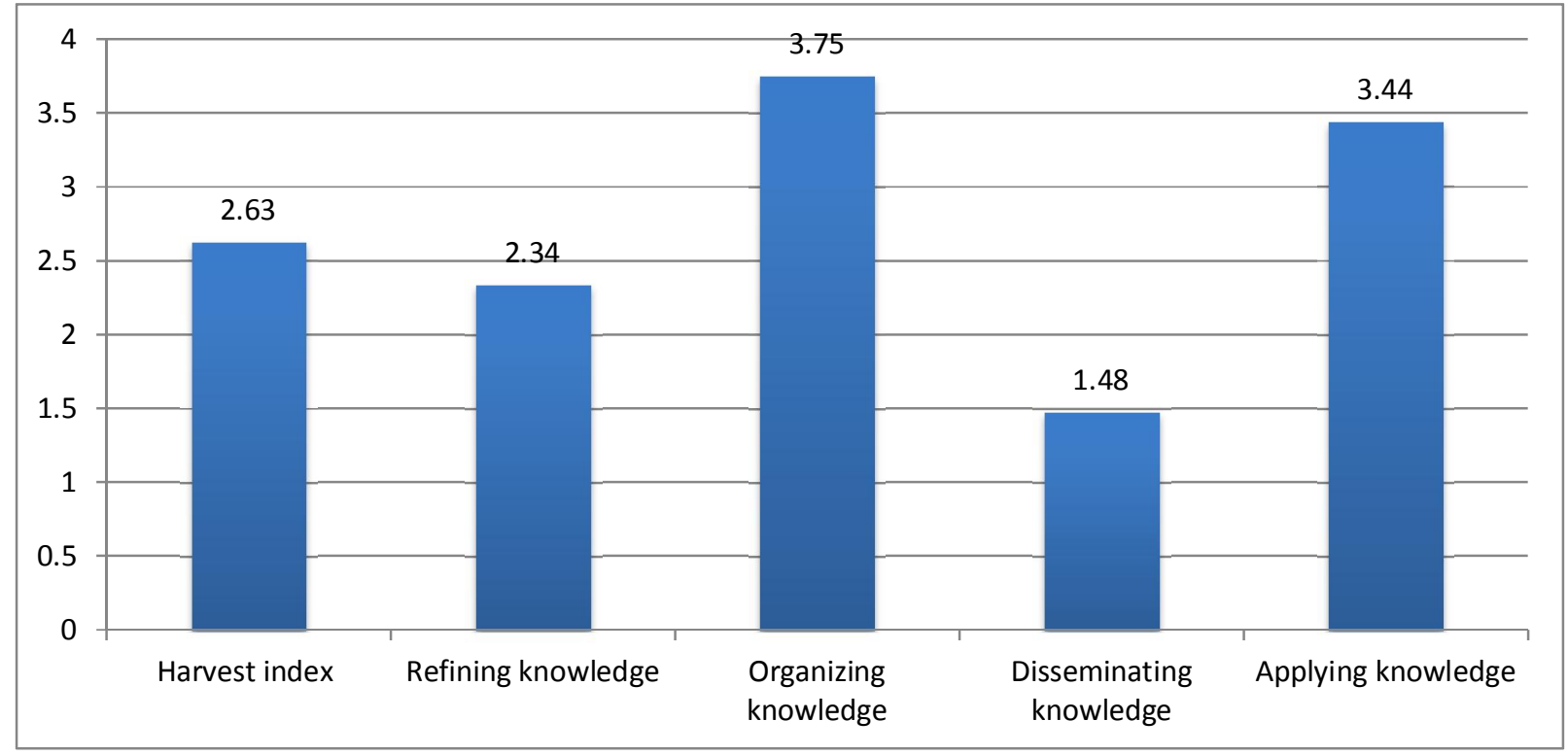

Fig. 2. The results of Freedman test 
The results of Freedman test indicates that organizing knowledge is number one priority followed by applying knowledge, harvesting index, refining knowledge and disseminating knowledge.

\section{Conclusion}

In this paper, we have presented an empirical investigation to study the relationship between organizational change and knowledge management. The proposed study of this paper has implemented Spearman test to verify the hypotheses of this survey and freedman test has been also applied to find the relative importance of each sub-hypotheses. The results of our survey have concluded that harvest index, refining knowledge, organizing knowledge, disseminating knowledge as well as applying knowledge had positive and meaningful impact on organizational change. Our investigation has also indicated that organizing knowledge had the most influential impact on organizational change and disseminating knowledge had the minimum influence on organizational change.

\section{Acknowledgement}

This research has been accomplished in a Cable and Wire producer in city of Semnan, Iran called Shahin and the authors would like to thank them for cordially cooperating with our team. We are also delighted for constructive comments on earlier version of this paper.

\section{References}

Battilana, J., Gilmartin, M., Sengul, M., Pache, A.C., \& Alexander, J.A. (2010). Leadership competencies for implementing planned organizational change. The Leadership Quarterly, 21(3), $422-438$.

Chiang, C.F. (2010). Perceived organizational change in the hotel industry: An implication of change schema. International Journal of Hospitality Management, 29(1), 157-167.

Klarner, P., By, R.T., \& Diefenbach, T. (2011). Employee emotions during organizational changeTowards a new research agenda. Scandinavian Journal of Management, 27(3), 332-340.

Lehman, W.E.K., Greener, J.M., \& Simpson, D.D. (2002). Assessing organizational readiness for change. Journal of Substance Abuse Treatment, 22(4), 197-209.

Peachey, J.W., \& Bruening, J. (2012). Investigating ambivalence towards organisational change in a Football Championship Subdivision intercollegiate athletic department. Sport Management Review, 15(2), 171-186.

Thomas, R., \& Hardy, C. (2011). Reframing resistance to organizational change. Scandinavian Journal of Management, 27(3), 322-331 